\title{
Mental and physical illness in caregivers: results from an English national survey sample
}

Lindsay Smith, Juliana Onwumere, Tom Craig, Sally McManus, Paul Bebbington and Elizabeth Kuipers

\section{Background}

Caregivers make a significant and growing contribution to the social and medical care of people with long-standing disorders. The effective provision of this care is dependent on their own continuing health.

\section{Aims}

To investigate the relationship between weekly time spent caregiving and psychiatric and physical morbidity in a representative sample of the population of England.

\section{Method}

Primary outcome measures were obtained from the Adult Psychiatric Morbidity Survey 2007. Self-report measures of mental and physical health were used, along with total symptom scores for common mental disorder derived from the Clinical Interview Schedule - Revised.

\section{Results}

In total, $25 \%(n=1883)$ of the sample identified themselves as caregivers. They had poorer mental health and higher psychiatric symptom scores than non-caregivers. There was an observable decline in mental health above $10 \mathrm{~h}$ per week. A twofold increase in psychiatric symptom scores in the clinical range was recorded in those providing care for more than $20 \mathrm{~h}$ per week. In adjusted analyses, there was no excess of physical disorders in caregivers.

\section{Conclusions}

We found strong evidence that caregiving affects the mental health of caregivers. Distress frequently reaches clinical thresholds, particularly in those providing most care. Strategies for maintaining the mental health of caregivers are needed, particularly as demographic changes are set to increase involvement in caregiving roles.

\section{Declaration of interest}

None.
Large numbers of people provide help and support to friends or relatives unable to manage as a result of old age or ill health. ${ }^{1}$ The latest figures from the 2011 Census record that one person in ten in England and Wales recognises themselves as a caregiver. ${ }^{2}$ The financial and social significance of these caregivers (also commonly referred to as unpaid or informal carers) is substantial, and growing. ${ }^{3}$ Over the past 10 years, the increase in caregiving has exceeded population growth in Britain, particularly for those providing greater amounts of care (over $20 \mathrm{~h}$ per week (hpw)). ${ }^{2}$ In the context of a community care approach and a prolonged recession, governments in many jurisdictions have prioritised development of policies directed at caregivers as they attempt to respond to the needs of rapidly ageing populations. ${ }^{4}$ In the UK a carers strategy recommends the early identification of individuals with caregiving responsibilities so that, both for their own benefit and that of the people they care for, they can be supported to maintain their physical and mental health. ${ }^{5}$ General practitioners have been targeted as a critical first point of contact in encouraging individuals to identify themselves as caregivers, and 'quick tools' are in development to assess levels of care provision and its impact on individuals. ${ }^{6,7}$ Appropriately controlled studies have generally shown that caregivers experience worse health than non-caregivers. ${ }^{8}$ Meta-analyses also report consistent associations between caregiving and poor mental health outcomes. ${ }^{9}$ However, effect sizes for physical health have been smaller, and fluctuate between impaired and improved physical health in caregivers relative to non-caregivers. ${ }^{10}$ Recent research has therefore focused on identifying predictors of the magnitude of the health impact of caregiving. ${ }^{11-16}$ We examined the relationship between the number of hours spent caregiving per week and physical and mental health, based on an English national sample (the 2007 Adult Psychiatric Morbidity Survey: APMS 2007). ${ }^{17}$ We hypothesised that those reporting higher amounts of caregiving would not only perceive their mental health as poorer than non-caregivers but would also report increased psychiatric symptomatology as assessed by a standardised clinical interview.

\section{Method}

\section{Sampling procedure}

The APMS 2007 survey employed a stratified, random probability sampling method to provide robust weighted data representative of the English adult population aged 16 and over. Interviews were conducted between October 2006 and December 2007. Private households were identified via the small user Postcode Address File (PAF). The small user PAF consists of all Royal Mail delivery points receiving fewer than 50 items of mail each day. It provides a comprehensive database of private households in England. The proportion of households living at addresses not on the PAF is estimated at less than $1 \%$. The primary sampling units were individual or grouped postcode sectors, which were stratified by regional area and markers of socioeconomic status. Delivery points were randomly selected within each postcode sector, based on probabilities calculated in proportion to size (the number of delivery points). Site visits yielded 13171 eligible addresses for inclusion, and one person over the age of 16 was selected from each identified household using the Kish grid method. ${ }^{18}$ A total of 7304 people $(57 \%$ of those potentially eligible, and $70 \%$ of those successfully contacted) completed interviews with trained representatives from NatCen Social Research. Information was collected on sociodemographic characteristics, general health, psychiatric symptoms and service use. Ethical approval for APMS 2007 was granted by the National Research Ethics Service. 


\section{Identifying caregivers}

Caregiving responsibilities were assessed by computer-assisted face-to-face interview. Individuals were asked whether or not they 'look after, or give help or support to family members, friends, neighbours or others because they have a long term physical or mental ill-health or disability, or problems related to age?' This definition is consistent with comparative surveys (Survey of Carers in Households 2009/2010, ${ }^{19}$ National Census 2011, ${ }^{20}$ General Households Survey 2000, ${ }^{21}$ now known as the General Lifestyle Survey) in avoiding use of the term 'carer' and in specifying long term, as opposed to temporary, illness. Participants were also asked to exclude anything which constituted paid employment. Respondents estimated hours spent caregiving per week on a nine-point categorical scale (hpw: 0-4, 5-9, 10-19, 20-34, 35-49, $50-90,>100,<10$ but varies, $>10$ but varies). The inclusion of $0 \mathrm{hpw}$ in the scale enabled individuals self-identifying as caregivers and engaged in a few hours of caregiving activity regularly on a monthly basis to be differentiated from non-caregivers. Travel time associated with caregiving tasks was included within these estimates.

\section{Clinical Interview Schedule - Revised}

The Clinical Interview Schedule - Revised (CIS-R) is a standardised clinical interview developed for administration by lay interviewers. ${ }^{22}$ It assesses psychiatric symptoms relating to specific diagnostic areas, such as depressive and somatic symptoms, generalised anxiety and social phobia. Filter questions establish the presence or absence of particular reference symptoms within the past month. Further questions assess frequency, severity and duration, and time since onset, and the instrument can be used to provide a total symptom score of $0-57$, an objective measure of affective disturbance, broadly defined. The accepted clinical threshold for psychiatric morbidity is $\geqslant 12 .^{23}$ To assess clinical significance, a fourfold categorisation, in addition to overall score, was used for analyses in the present study $(0-6,7-11,12-17,18+)$. Analyses relating to individual ICD-10 diagnoses will be examined elsewhere (details available from the authors on request).

\section{Medical Outcomes Study Short Form Health Survey}

The Medical Outcomes Study Short Form Health Survey (SF-12) is a self-report questionnaire assessing perceived general health and well-being. It represents a subset of items from the 36-item Short Form (SF-36). The original scale has demonstrated reliability, validity and sensitivity in discriminating changes across patient groups. ${ }^{24,25}$ Correlations between the SF-12 and SF-36 have been reported at $r>0.94$ and the shortened scale has been cross-validated across countries and age groups. ${ }^{26,27}$ Items in the SF-12 form eight health domains that are in turn used to calculate aggregate scores for physical and mental health, with higher scores indicating perceptions of better health. ${ }^{28,29}$ Norm-based scoring was employed, using US population norms, which have demonstrated applicability to UK populations. ${ }^{30,31}$

\section{Chronic physical conditions}

Individuals endorsed the presence or absence of a series of 21 chronic physical conditions in the preceding year. The APMS uses a show card to ensure comprehensive coverage of physical conditions that people may not otherwise think to mention (for example problems with skin or hearing). The list comprised cancer, diabetes, epilepsy, migraine, cataracts/eyesight problems, hearing difficulties, stroke, heart attack, high blood pressure, bronchitis, asthma, allergy, ulcers, liver problems, bowel/colon problems, bladder problems, arthritis, bone, back or joint problems, infectious disease and skin problems. The card additionally includes a clause stipulating that the condition must have been present in adulthood and diagnosed by a health professional.

\section{Statistical analysis}

The 'Survey' commands in Stata 10 for Windows were used as they provide robust estimates of variance in complex data-sets. Weights were calculated to provide a representative national sample, taking into account survey design and non-response. For more information on the weighting system, see the main APMS report. ${ }^{32}$ In the present study, actual counts are presented, together with weighted means and proportions and 95\% confidence intervals as estimates of variance. To reduce standard error, the categories denoting hours spent caregiving per week were combined to form five groups for descriptive and inferential statistical analyses $(0-9,10-19,20-34,35-99,>100 \mathrm{hpw})$. This was further reduced to three groups (non-caregivers, 0-19 hpw and $\geqslant 20 \mathrm{hpw}$ ) when comparing proportions of people meeting clinical thresholds for psychiatric symptoms because of low numbers at higher symptom levels. Group differences were assessed with uncorrected chi-squared and design-based ANOVA tests. Multiple regression analyses were conducted to examine the relationship between caregiving hours and health outcomes, taking into account putative confounding factors, identified from the existing literature and confirmed by correlation analyses (age, gender, employment status, marital status, social support, smoking status, daily alcohol consumption and body mass index). Unstandardised coefficients are quoted.

\section{Results}

\section{Frequency of caregiving}

A total of $25 \%(n=1883)$ of participants identified themselves as regular caregivers (Table 1$)$, of whom nearly all $(n=1874)$ gave an indication of the number of hours per week they were engaged in caregiving activities. Participants who did not quantify time spent caregiving $(n=9)$ and those who indicated that their hours varied $(>10 \mathrm{~h})$ on a weekly basis $(n=46)$ were excluded from analyses.

Women were significantly more likely than men to identify themselves as caregivers $\left(\chi^{2}=10.3\right.$, d.f. $\left.=1, P<0.01\right)$ and to be engaged in higher levels of caregiving activities $\left(\chi^{2}=28.7\right.$, d.f. $=5, P<0.0005)$. In addition, caregivers were more likely to be married $\left(\chi^{2}=31.9\right.$, d.f. $\left.=1, P<0.0001\right)$ and to be unemployed or not to have worked in the past year $\left(\chi^{2}=9.9\right.$, d.f. $\left.=3, P<0.05\right)$. In total, $4.4 \%$ of the sample reported providing care for more than $20 \mathrm{hpw}$. The mean age in this group was significantly higher than for those providing less care $(0-19 \mathrm{hpw})$ and for non-caregivers $(F(5,256)=14.0, P<0.0001)$.

\section{Measures of mental and physical health}

Perceived mental health (SF-12 mental health summary scores) was significantly correlated with total scores on the CIS-R $r=-0.54$, $P<0.0001)$. Likewise, perceived physical health (SF-12 physical health summary scores) was significantly correlated with the number of diagnosed physical conditions reported by individuals in the preceding year $(r=-0.47, P<0.0001)$.

\section{Mental health}

Even after adjustment for relevant confounding factors in multivariate regression (physical health summary scores, age, 
Table 1 Frequency of caregiving: demographic analyses by number of hours spent caregiving ${ }^{a}$

\begin{tabular}{|c|c|c|c|c|c|c|c|c|c|}
\hline & \multicolumn{3}{|c|}{ Participants } & \multicolumn{6}{|c|}{ Caregivers grouped by hours per week (hpw) spent caregiving ${ }^{\mathrm{b}}$} \\
\hline & Non-caregivers & All caregivers & $P$ & 0-9 hpw & 10-19 hpw & 20-34 hpw & 35-99 hpw & $\geqslant 100 \mathrm{hpw}$ & $P$ \\
\hline Total participants, \% & 75.1 & 24.9 & & 17.1 & 2.9 & 1.4 & 1.6 & 1.4 & \\
\hline Unweighted count & $5520 / 7403$ & $1883 / 7403$ & & $1288 / 7348$ & $216 / 7348$ & $110 / 7348$ & $114 / 7348$ & $100 / 7348$ & \\
\hline Age, mean & 45.3 & 49.5 & $<0.0001$ & 48.7 & 48.4 & 49.4 & 51.7 & 55.6 & $<0.0001$ \\
\hline Gender, \% female & 50.3 & 54.6 & $<0.01$ & 51.3 & 58.9 & 62.7 & 65.6 & 64.2 & $<0.0005$ \\
\hline Marital status, \% & & & $<0.0001$ & & & & & & $<0.0001$ \\
\hline Married/cohabiting & 61.0 & 68.4 & & 68.3 & 61.2 & 64.9 & 72.4 & 79.1 & \\
\hline Single/separated/divorced/widowed & 39.0 & 31.6 & & 31.7 & 38.9 & 35.1 & 27.6 & 20.9 & \\
\hline Number of individuals in household, \% & & & $<0.0001$ & & & & & & $<0.0001$ \\
\hline 1 & 16.7 & 12.0 & & 13.4 & 14.4 & 12.2 & 5.1 & 2.5 & \\
\hline 2 & 36.8 & 46.1 & & 44.6 & 39.9 & 50.0 & 51.0 & 57.8 & \\
\hline$\geqslant 3$ & 46.5 & 41.9 & & 42.0 & 45.7 & 37.8 & 43.9 & 39.7 & \\
\hline Employment, \% & & & 0.05 & & & & & & $<0.0001$ \\
\hline Manager/professional & 29.7 & 26.4 & & 29.9 & 26.8 & 21.1 & 8.2 & 10.8 & \\
\hline Intermediate & 7.3 & 6.5 & & 6.9 & 6.4 & 6.6 & 2.2 & 5.0 & \\
\hline Office/manual & 31.7 & 33.2 & & 34.8 & 33.7 & 36.4 & 36.4 & 14.5 & \\
\hline $\begin{array}{l}\text { Never worked/ } \\
\text { not worked in last year }\end{array}$ & 31.3 & 33.9 & & 28.4 & 33.1 & 36.0 & 53.2 & 69.7 & \\
\hline Current smoker, \% & 22.9 & 23.8 & ns & 23.6 & 23.7 & 25.9 & 25.6 & 23.4 & ns \\
\hline Alcohol, standard drinks per day: \% & & & $<0.05$ & & & & & & $<0.005$ \\
\hline 0 & 17.7 & 16.4 & & 13.8 & 19.9 & 11.3 & 22.4 & 30.0 & \\
\hline $1-4$ & 62.6 & 65.9 & & 68.1 & 60.7 & 70.6 & 59.0 & 58.6 & \\
\hline $5-6$ & 10.6 & 10.7 & & 10.8 & 13.9 & 13.5 & 9.3 & 5.7 & \\
\hline$\geqslant 7$ & 9.1 & 7.0 & & 7.3 & 5.6 & 4.5 & 9.4 & 5.8 & \\
\hline Body mass index, mean & 25.9 & 26.5 & $<0.005$ & 26.3 & 25.9 & 27.4 & 27.5 & 27.7 & $<0.01$ \\
\hline $\begin{array}{l}\text { Number of close contacts } \\
\text { (social support), mean }\end{array}$ & 13.0 & 13.6 & $<0.05$ & 13.7 & 12.6 & 14.3 & 14.1 & 13.5 & ns \\
\hline $\begin{array}{l}\text { ns, non-significant. } \\
\text { a. Weighted percentages given for all proporti } \\
\text { b. For exclusions, see Results: Frequency of ce }\end{array}$ & $\begin{array}{l}\text { ion estimates } \\
\text { aregiving. }\end{array}$ & & & & & & & & \\
\hline
\end{tabular}

gender, employment status, marital status, social support, daily alcohol consumption and body mass index), caregivers had significantly higher total scores on the CIS-R than non-caregivers (Table 2). A dose-effect was observable for the amount of caregiving. When the proportions of people reaching clinical thresholds for psychiatric symptoms were compared (Table 3), participants engaged in greater amounts of caregiving $(\geqslant 20 \mathrm{hpw})$ were twice as likely as non-caregivers to report CIS-R scores of 12 or more.

Results for perceived mental health (SF-12 mental health summary scores) were consistent with CIS-R derived measures of psychiatric morbidity (Table 4). Examination of unweighted mean scores on the CIS-R and SF-12 indicated a progressive rate of decline in mental health beyond $10 \mathrm{hpw}$ of caregiving (Fig. 1). On both measures, there is a suggestion that people in the second highest category of amount of caregiving (35-99 hpw) have better mental health than those in the category immediately below (25-34 hpw).

\section{Physical health}

Caregivers reported experiencing a higher mean number of physical illnesses in the preceding year than non-caregivers (non-caregivers: mean $0.86,95 \% \mathrm{CI} 0.82-0.90,0-19 \mathrm{hpw}$ caregiving: mean $0.98,95 \%$ CI $0.92-1.04, P<0.005$; $\geqslant 20$ hpw caregiving: mean $1.16,95 \%$ CI $1.02-1.30, P<0.0001)$. However, although group differences were significant when tested in unadjusted regression analyses, they ceased to be so after controlling for potential confounding factors.

Unadjusted regression analyses of the relationship between hours spent caregiving and the standardised SF-12 physical health summary scores were also carried out. In comparison with noncaregivers, people engaged in higher amounts of caregiving $(\geqslant 20 \mathrm{hpw})$ reported significantly poorer perceived physical health $(\mathrm{B}=-1.26,95 \% \mathrm{CI}-2.42$ to $-0.11, P=0.03)$. This association was non-significant for lower amounts of caregiving (0-19 hpw, $P>0.05$ ). Following the introduction of putative confounding factors in the regression (mental health summary scores, gender, age, marital status, employment status, daily alcohol consumption, body mass index and social support), higher amounts of caregiving were actually associated with better physical health summary scores, albeit not significantly so (0-19hpw: $\mathrm{B}=0.31,95 \%$ CI -0.25 to $0.87, P>0.05$ and $\geqslant 20 \mathrm{hpw}$ : $\mathrm{B}=0.96,95 \% \mathrm{CI}-0.19$ to $2.11, P>0.05)$. Participants' age, employment status and body mass index contributed most to the variance in mental health summary scores.

\section{Discussion}

\section{Frequency of caregiving}

One in four people aged over 16 in households identified themselves as a caregiver during the APMS 2007 interviews. This is twice the weighted rate reported by the Survey of Carers in Households 2009/2010 (10.9\%) $)^{2}$ and by the UK Census 2001 $(10.0 \%) .^{34}$ This discrepancy might relate to the survey questions, to context, or to the sampling design. The Survey of Carers in Households 2009/2010 notes for example the potential for its methodological approach to underestimate 'lighter touch' or lower intensity caregiving. ${ }^{19}$ Frequencies obtained by interviews conducted with a respondent 'nominated by the householder' (as was the case for the Survey of Carers in Households) are likely 


\begin{tabular}{|c|c|c|c|c|}
\hline Amount of caregiving, hours per week (hpw) & $\begin{array}{l}\text { CIS-R total score, } \\
\text { weighted mean }\end{array}$ & $\begin{array}{l}\text { Unstandardised coefficient (B) } \\
\qquad(95 \% \mathrm{Cl})\end{array}$ & $t$-value & $P$ \\
\hline Non-caregivers & 4.7 & - & - & - \\
\hline 0-9 hpw & 5.6 & $1.3(0.90-1.77)$ & 6.0 & $<0.0001$ \\
\hline 10-19 hpw & 7.9 & $3.1(2.00-4.16)$ & 5.6 & $<0.0001$ \\
\hline 20-34 hpw & 8.1 & $2.9(1.46-4.38)$ & 4.0 & $<0.0001$ \\
\hline 35-99 hpw & 7.1 & $2.7(1.48-3.98)$ & 4.3 & $<0.0001$ \\
\hline$\geqslant 100 \mathrm{hpw}$ & 8.5 & $4.0(2.31-5.79)$ & 4.6 & $<0.0001$ \\
\hline
\end{tabular}

Table 3 Psychiatric symptom score (Clinical Interview Schedule - Revised, CIS-R) by amount of caregiving: proportion of individuals meeting clinical thresholds for disorder $(\geqslant 12)^{\mathrm{a}}$

\begin{tabular}{llcccc} 
& \multicolumn{5}{c}{ CIS-R overall score fourfold categorisation, weighted \% $(95 \% \mathrm{Cl})^{\mathrm{b}}$} \\
\cline { 2 - 6 } Amount of caregiving, hours per week (hpw) & $0-6$ & $7-11$ & $12-17$ & $\geqslant 18$ & Totals \\
\hline Non-caregivers & $70.40(68.88-71.88)$ & $16.35(15.17-17.60)$ & $\mathbf{6 . 7 3}(5.99-7.54)$ & $\mathbf{6 . 5 2}(5.87-7.24)$ & 100 \\
\hline $0-19 \mathrm{hpw}$ & $63.49(60.69-66.20)$ & $17.79(15.76-20.02)$ & $\mathbf{9 . 3 4}(7.74-11.25)$ & $\mathbf{9 . 3 8}(7.94-11.06)$ & 100 \\
\hline$\geqslant 20 \mathrm{hpw}$ & $50.18(44.55-55.79)$ & $21.29(16.71-26.72)$ & $13.50(9.97-18.03)$ & $\mathbf{1 5 . 0 3}(11.85-18.89)$ & 100 \\
$\begin{array}{l}\text { a. Bold indicates significance. } \\
\text { b. Overall: } \chi^{2}=94.65, \text { d.f. }=6, P<0.00001 .\end{array}$ & & & & \\
\end{tabular}

\begin{tabular}{|c|c|c|c|}
\hline Amount of caregiving (hours per week, hpw) & $\begin{array}{l}\text { SF-12 mental health summary } \\
\text { score, weighted mean }\end{array}$ & $\begin{array}{l}\text { Unstandardised coefficient } \\
\text { (B) }(95 \% \mathrm{Cl})\end{array}$ & $P$ \\
\hline Non-caregivers & 42.9 & - & - \\
\hline 0-9 hpw & 42.6 & $-0.7(-1.04$ to -0.30$)$ & 0.001 \\
\hline 10-19 hpw & 41.4 & $-2.0(-2.89$ to -1.06$)$ & $<0.001$ \\
\hline 20-34 hpw & 40.4 & $-2.5(-3.71$ to -1.25$)$ & $<0.001$ \\
\hline 35-99 hpw & 40.6 & $-2.5(-3.77$ to -1.30$)$ & $<0.001$ \\
\hline$\geqslant 100 \mathrm{hpw}$ & 39.7 & $-4.2(-6.11$ to -2.26$)$ & $<0.001$ \\
\hline
\end{tabular}
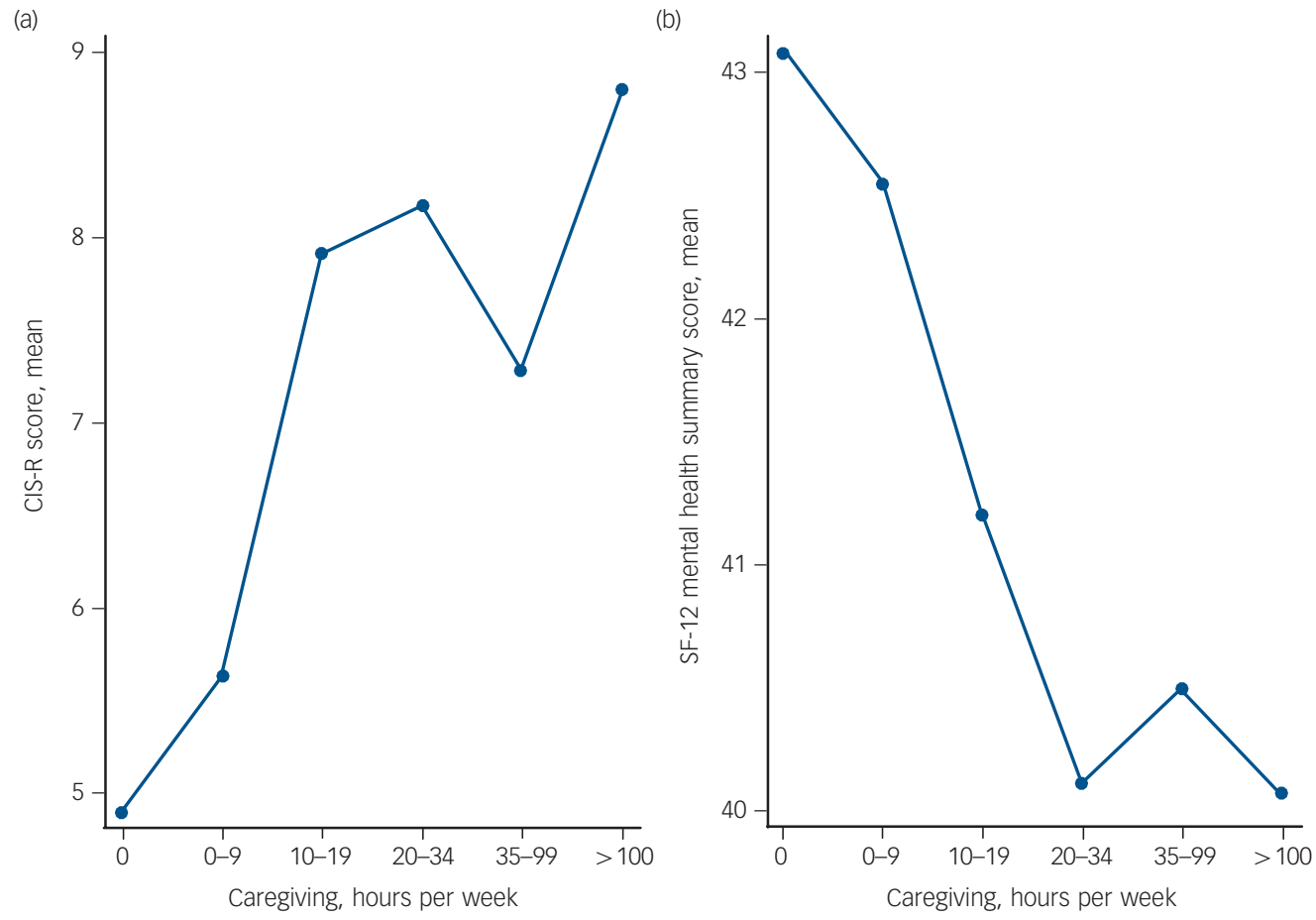

Fig. 1 (a) Psychiatric symptom score on the Clinical Interview Schedule - Revised (CIS-R) and (b) standardised perceived mental health score on the 12-item Short Form (SF-12) by amount of caregiving (unweighted means). 
to differ from those where all members of the household are interviewed. ${ }^{34}$ Both the General Household Survey $(2000 / 2001)^{21}$ and the British Household Panel Survey $(2007)^{35}$ used the latter approach, and obtained somewhat higher age-standardised estimates for the caregiving population, at $16.1 \%$ and $17.0 \%$ respectively (see Appendix $\mathrm{C}$ of the Survey of Carers in Households ${ }^{19}$ ). In the APMS, one member was selected at random from each household and weighting was used to render the sample representative of the adult population in England. Using this robust approach, it also reports a larger caregiving population. The excess in the frequency of caregivers is restricted to those engaged in fewer caregiving hours per week (0-19hpw). Rates of individuals engaged in higher amounts of caregiving $(\geqslant 20$ hpw) are relatively consistent (APMS 2007: 4.4\%, Survey of Carers in Households 2009/2010: 5.2\%; ${ }^{19}$ Census 2001: 3.9\%, ${ }^{33}$ General Households Survey 2000: $4.1 \%{ }^{21}$ ). Contrary to the Census, which identifies individuals taking part in at least $1 \mathrm{hpw}$ caregiving, the APMS includes $0 \mathrm{hpw}$ in its first category. This allowed for people providing regular caregiving of less than $4 \mathrm{~h}$ over a monthly period, and may account for the higher frequency of people taking part in lower amounts of caregiving. Alternatively, political and media attention may have influenced public acknowledgment of everyday activities as constituting 'caregiving. However, this might be expected to affect all surveys equally. If, nevertheless, the difference indicates early-stage caregiving in relation to an ageing population, it should be noted.

Corresponding increases in higher amounts of caregiving might, in consequence, be expected in the future. Indeed, although age-standardised rates of caregiving from the 2011 Census (completed after the APMS 2007) are yet to be released, provisional analyses suggest that the greatest rate of growth in the caregiving population over the past 10 years has been observed in those providing more than $20 \mathrm{hpw}$ of care. At least for higher levels of care, most caregiving relationships in the APMS 2007 involved the provision of care by older participants. This is reflected in the predictive influence of age in the multivariate regression of physical health outcomes. Direct comparisons of caregiving data from the 2011 and 2001 Censuses should provide more accurate estimations of change statistics, with forthcoming releases expected from the Office for National Statistics' beta testing project: 'Characteristics of and living arrangements amongst informal carers at the 2011 and 2001 Censuses: stability, change and transition'.

\section{Impact of caregiving}

As predicted, caregiving was significantly associated with poorer mental health outcomes. This relationship remained robust in regression analyses even after the inclusion of confounding factors. The causal direction is unclear. Increased psychiatric symptomatology and rates of common mental disorder in caregivers may reflect shared vulnerabilities that have led biologically and socially related care-recipients to require support themselves. However, a number of considerations suggest that the mental health correlates are responses to the caregiving role. First, a relatively objective measure of amount of caregiving (number of hours per week) was used, as opposed to scaled measures of subjective feelings of burden ${ }^{12}$ that are likely to have a higher correlation with psychological distress. ${ }^{10}$ Second, a significant and sizeable dose-effect in relation to amount of time devoted to caregiving per week was observed, with more pronounced declines in mental health observed at upwards of $10 \mathrm{hpw}$ and also at greater than $100 \mathrm{hpw}$ spent caregiving. This is consistent with studies analysing trajectories of caregiving in earlier national samples, ${ }^{36,37}$ and is difficult to interpret in terms of self-selection of psychiatrically disadvantaged people into the caring role. Third, again in line with previous studies, the relationship reported between caregiving and physical health was inconsistent, being significantly affected by moderating factors. The caregivers in question are older than the national average, and older populations generally have worse physical but better mental health than the average. $^{40,41}$ The fact that this pattern was so different in caregivers is difficult to explain in terms of selection, and therefore makes a direct effect of the caregiving role on mental health a more likely explanation.

Caution is nevertheless advisable in interpreting the clinical significance of the dose-response relationship between hours per week spent caregiving and severity of psychiatric symptoms. A limitation associated with categorising caregivers according to hours spent caregiving is that it may implicitly suggest a uniform impact of care associated with 1-unit h. Caring for people with mental as well as physical health problems is known to be associated with higher levels of distress than caring for those with physical health issues alone. ${ }^{40}$ This distress may accordingly be experienced at lower amounts of caregiving, which further justifies the inclusion of individuals who identify as carers but who quantify their regular level of caregiving activity at less than $1 \mathrm{hpw}$ (i.e. $0 \mathrm{hpw}$ ). The observed dose-response relationship may therefore be moderated by variables such as care-recipient illness, kinship and face-to-face contact time. It may also be affected by changes in available resources and competing demands. A partial reversal in declining CIS-R scores associated with increased caregiving hours was observed at the second highest amount of caregiving (35-99 hpw). This might be explained by changes in compounding stressors including employment as people retire and take on greater caregiving activities associated with older age. A substantial increase in the proportion of people not having worked in the past year was observed in those endorsing 35-99 hpw caregiving in comparison with lower amounts of care (Table 1). It may alternatively indicate some psychological adjustment to the stresses associated with caregiving as hypothesised in stress-appraisal-coping models. ${ }^{41}$

We anticipated that greater data capture in the $0-19 \mathrm{hpw}$ caregiving group in comparison with previous surveys might accentuate reported differences in outcome measures when compared with individuals engaged in higher amounts of caregiving $(\geqslant 20 \mathrm{hpw}$ ). This provided one rationale for ensuring that comparisons in outcome measures were made across at least three groups of caregivers (including non-caregivers). However, a dose-response relationship was consistently observed between amount of caregiving and health outcomes in comparisons based on a three-group split and a five-group split. Nevertheless, withingroup variation in the levels of distress experienced per unit hour of caregiving activity should not be underestimated.

\section{Limitations}

The data relied on self-report, without collateral corroboration. This might lead to underreporting of physical conditions: participants may have undiagnosed symptoms, or they may be unaware or forgetful of a previous diagnosis. However, the requirement that physical conditions had been diagnosed by a health professional should increase consistency by constraining the ailments included. The validity of findings from self-report measures is also supported by the significant correlations between perceived and observer-rated measures of physical and mental health. Furthermore, self-reported mental health has intrinsic value as an indicator of psychological distress, particularly given the central role of subjective carer appraisals in cognitive models of carer burden or the impact of care. ${ }^{41,42}$ The study also relied on self-report for measuring time spent caregiving. Although this method has been 
validated, it may lead to overestimations or underestimations of caregiving levels and is less accurate than diary techniques. ${ }^{43}$ In addition, the APMS survey did not assess some important characteristics of caregiving roles, which we were therefore unable to analyse in relation to physical and mental health. These included the basis of the relationship between caregiver and care-recipient, whether they lived together, the duration of the caregiving role and the care-recipient's type of illness. Our findings therefore relate to the generality of caregiving: caring for people with specific problems may result in specific patterns of impact. Finally, the data were obtained cross-sectionally, which limits causal inference.

\section{Implications}

We have demonstrated the significant health consequences of caregiving, even at lower levels of care. This is relevant to approximately 5.8 million people in England and Wales who currently identify themselves as caregivers. ${ }^{2}$ For individuals providing more than $20 \mathrm{hpw}$ of care (over 2 million in England according the 2011 Census), ${ }^{20}$ the mean excess score in comparison with non-caregivers was three points on the CIS-R. By contrast, the equivalent change in CIS-R score in relation to the unpleasant experience of job loss was zero in two-thirds of participants, and around one for most of the remainder. ${ }^{44}$ Moreover, the proportion of individuals meeting clinical thresholds for psychiatric symptoms in this group was twice that observed in non-caregivers.

Our results indicate, first, the need for pre-emptive policies to identify caregivers at an early stage and to target support services appropriately. This raises the issue of how best to identify and communicate with caregivers at an early stage. Second, although varying definitions of caregiving might lead to variations in reported frequency, the present study affirms that objective measures of caregiving demand (hours per week) are informative. Hence, we recommend their inclusion in the quick assessment instruments being developed for caregivers. ${ }^{6,7}$ Finally, understanding differences in the effect of caregiving roles in relation to individuals with different mental and physical conditions will help services to provide targeted information and support to enable families to cope effectively.

Although these considerations will apply across jurisdictions, recent developments in the UK are of interest. The government is embarking on an ambitious new public health strategy that stipulates 'No health without mental health' ${ }^{45}$ and which centres on the devolution of public health governance to local communities (including the Health and Social Care Act 2012). 'Carers at the Heart of 21st-Century Families and Communities' is the title of the current UK Carers Strategy. ${ }^{46}$ The Department of Health has funded a 'Supporting Carers in GPs programme' and, in association with the Royal College of General Practitioners, has conducted a pilot training programme (2010) for general practitioners on best practice in incorporating a carers policy. ${ }^{47,48}$ Carers UK continues to train volunteer 'carer ambassadors' to act as liaison officers in directing this policy in practice. ${ }^{49}$ However, despite positive feedback on the pilot, it was noted by participants that 'services for carers were unlikely to improve significantly without incentives and additional resource. ${ }^{46}$ General practitioners are already taking on increased duties in administering the clinical commissioning groups proposed by the Health and Social Care Bill. In addition, evidence suggests that taking on a caregiving role does not necessarily translate into increased contact with primary care service. ${ }^{50}$ The development of tangible actions to identify and engage caregivers remains a priority.
Lindsay Smith, MA, MSC, Juliana Onwumere, PhD, DClinPsy, Department of Psychology, Institute of Psychiatry, King's College London; Tom Craig, MBBS, PhD, FRCPsych, Department of Health Services and Population Research, Institute of Psychiatry, King's College London; Sally McManus, MSc, NatCen Social Research London; Paul Bebbington, PhD, FRCP, FRCPsych, Unit of Mental Health Sciences, Faculty of Brain Sciences, University College London Medical School, London;
Fond Elizabeth Kuipers, PhD, FBPS, AcSS, Department of Psychology, Institute of Psychiatry,

King's College London and NIHR Biomedical Research Unit at the South London and Maudsley NHS Foundation Trust, London, UK

Correspondence: Lindsay Smith, Department of Psychology, Institute of Psychiatry, King's College London, De Crespigny Park, London SE5 8AF, UK. Email: lindsay.smith@kcl.ac.uk

First received 30 Dec 2013, final revision 4 Mar 2014, accepted 14 Mar 2014

\section{References}

1 Shahly V, Chatterji S, Gruber MJ, Al-Hamzawi A, Alonso J, Andrade LH, et al. Cross-national differences in the prevalence and correlates of burden among older family caregivers in the World Health Organization World Mental Health (WMH) Surveys. Psychol Med 2013, 43: 1-15.

2 White C. 2011 Census Analysis: Unpaid Care in England and Wales, 2011 and Comparison with 2001. Office for National Statistics, 2013 (http:// www.ons.gov.uk/ons/dcp171766_300039.pdf).

3 Colombo F, Llena-Nozal A, Mercier J, Tjadens F. Help Wanted? Providing and Paying for Long-Term Care: Providing and Paying for Long-Term Care. OECD Publishing, 2011 (http://dx.doi.org/10.1787/9789264097759-en).

4 Christensen K, Doblhammer G, Rau R, Vaupel JW. Ageing populations: the challenges ahead. Lancet 2009; 374: 1196-208.

5 Department of Health. Recognised, Valued and Supported: Next Steps for the Carers Strategy. Department of Health, 2010 (https://www.gov.uk/ government/publications/recognised-valued-and-supported-next-steps-forthe-carers-strategy).

6 Cameron ID, Aggar C, Robinson AL, Kurrle SE. Assessing and helping carers of older people. BMJ 2011; 343: 1756-833.

7 Cormac I, Tihanyi P. Meeting the mental and physical healthcare needs of carers. Adv Psychiatr Treat 2006; 12: 162-72.

8 Schulz R, Sherwood PR. Physical and mental health effects of family caregiving. Am J Nurs 2008; 108: 23-7.

9 Pinquart M, Sörensen S, Stress P. Differences between caregivers and noncaregivers in psychological health and physical health: a meta-analysis. Psychol Aging 2003; 18: 250-67.

10 Vitaliano PP, Zhang J, Scanlan, JM. Is caregiving hazardous to one's physical health? A meta-analysis. Psychol Bull 2003; 129: 946-72.

11 Pinquart M, Sörensen S. Correlates of physical health of informal caregivers: a meta-analysis. J Gerontol B Psychol Sci Soc Sci 2007; 62: 126-37.

12 Buyck J-F, Bonnaud S, Boumendil A, Andrieu S, Bonenfant S, Goldberg M, et al. Informal caregiving and self-reported mental and physical health: results from the Gazel Cohort Study. Am J Public Health 2011; 101: 1971-9.

13 Phillips AC, Gallagher S, Hunt K, Der G, Carroll D. Symptoms of depression in non-routine caregivers: the role of caregiver strain and burden. $\mathrm{Br} J \mathrm{Clin}$ Psychol 2009; 48: 335-46.

14 Schulz R, Visintainer P, Williamson GM. Psychiatric and physical morbidity effects of caregiving. J Gerontology 1990; 45: 181-91.

15 Cooper C, Balamurali TBS, Livingston G. A systematic review of the prevalence and covariates of anxiety in caregivers of people with dementia. Int Psychogeriatr 2007; 19: 175-95.

16 Cuijpers P. Depressive disorders in caregivers of dementia patients: a systematic review. Aging Ment Health 2005; 9: 325-30.

17 National Centre for Social Research and University of Leicester. Adult Psychiatric Morbidity Survey, 2007 (3rd edn). UK Data Archive, 2011 (http://discover.ukdataservice.ac.uk/catalogue/?sn = 6379\&type = Data\%20 catalogue).

18 Kish L. A procedure for objective respondent selection within the household. J Am Statist 1949, 44: 380-7.

19 Department for Health. Survey of Carers in Households. NHS Information Centre for Health and Social Care, 2010 (http://www.hscic.gov.uk/PUB02200/ surv-care-hous-eng-2009-2010-rep1.pdf).

20 Office for National Statistics. 2011 Census in England and Wales: Glossary. UK Data Service Census Support (http://www.ons.gov.uk/ons/guide-method/ census/2011/census-data/2011-census-user-guide/glossary/index.html).

21 Maher J, Green H. Carers 2000: results from the carers module of the General Household Survey 2000. TSO, 2002. 
22 Lewis G, Pelosi AJ, Araya RC, Dunn G. Measuring psychiatric disorder in the community: a standardised assessment for use by lay interviewers. Psycho Med 1992; 27: 765-74.

23 Bebbington $\mathrm{P}$, Brughra $T$, Meltzer, $\mathrm{H}$, Farrell $\mathrm{M}$, Ceresa $\mathrm{C}$, Jenkins $\mathrm{R}$, Lewis $\mathrm{G}$. Psychiatric disorder and dysfunction in the UK National Survey of Psychiatric Morbidity. Soc Psychiatry and Psychiatr Epidemiol 2000; 35: 191-7.

24 McHorney CA, Ware JE, Lu JF, Sherbourne CD. The MOS 36-item Short Form Health Survey (SF-36): III. Tests of data quality, scaling assumptions and reliability across diverse patient groups. Med Care 1994; 32: 40-66.

25 Hays RD, Sherbourne CD, Mazel RM. The rand 36-item health survey 1.0 Health Econ 1993; 2: 217-27.

26 Gandek B, Ware JE, Aaronson NK, Apolone G, Bjorner JB, Brazier JE, et al. Cross-validation of item selection and scoring for the SF-12 Health Survey in nine countries: results from the IQOLA Project. International Quality of Life Assessment. J Clin Epidemiol 1998; 51: 1171-8.

27 Ware JE, Gandek B, Kosinski M, Aaronson NK, Apolone G, Brazier J, et al. The equivalence of SF-36 summary health scores estimated using standard and country specific algorithms in 10 countries: results from the IQOLA Project. International Quality of Life Assessment. J Clin Epidemiol 1998; 51: 1167-70.

28 McHorney CA, Ware JE, Raczek AE. The MOS 36-Item Short-Form Health Survey (SF-36): II. Psychometric and clinical tests of validity in measuring physical and mental health constructs. Med Care 1993; 31: 247-63.

29 Wilson D, Parsons J, Tucker G. The SF-36 summary scales: problems and solutions. Soz Präventivmed 2000; 45: 239-46.

30 Burholt V, Nash P. Short Form 36 (SF-36) Health Survey Questionnaire: normative data for Wales. J Public Health (Oxf) 2011; 33: 587-603.

31 Jenkinson $\mathrm{C}$. Comparison of UK and US methods for weighting and scoring the SF-36 summary measures. J Public Health Med 1999; 21: 372-6.

32 McManus S, Meltzer H, Brugha T, Bebbington $\mathrm{P}$, Jenkins R. Adult Psychiatric Morbidity in England, 2007: Results of a Household Survey. NHS Information Centre for Health and Social Care, 2009 (http://www.ic.nhs.uk/pubs/ psychiatricmorbidity07)

33 Young H, Grundy E, Kalogirou S. Who cares? Geographic variation in unpaid caregiving in England and Wales: evidence from the 2001 Census. Popul Trends 2005; 120: 23-34.

34 King D, Balarajan M, Blake M, Cheshire H, Darton R, Gray M, et al. Developing Improved Survey Questions on Older People's Receipt of, and Payment for, Formal and Informal Care. Personal Social Services Research Unit Discussion Paper (2764). London School of Economics and Political Science, 2010.

35 Lynn P. Quality Profile: British Household Panel Survey, Version 2.0: Waves 1-13, 1991-2003. University of Essex, 2006 (http://www.iser.essex.ac.uk/ bhps/quality-profile).

36 Legg L, Weir C, Langhorne $\mathrm{P}$, Smith L, Stott D. Is informal caregiving independently associated with poor health? A population-based study. J Epidemiol Community Health 2013; 67: 95-7.
37 Hirst M. Carer distress: a prospective, population-based study. Soc Sci Med 2005; 61: 697-708.

38 Spiers N, Bebbington PE, McManus S, Brugha T, Jenkins R, Meltzer H. Age and birth cohort differences in the prevalence of common mental disorder in England: the National Psychiatric Morbidity Surveys, 1993 to 2007. Br J Psychiatry 2011; 198: 479-84.

39 Jorm AF. Does old age reduce the risk of anxiety and depression? A review of epidemiological studies across the adult life span. Psych Med 2000; 30: $11-22$

40 Singleton N, Maung N, Cowie A, Sparks J, Bumpstead R, Meltzer H. Mental Health of Carers. TSO, 2002 (http://collection.europarchive.org/tna/ 20090106142604/http://statistics.gov.uk/downloads/theme_health/Mental_ Health_of_Carers_June02.pdf).

41 Lazarus RS, Folkman S. Stress, Appraisal, and Coping. Springer Publishing Company, 1984.

42 Szmukler Gl, Burgess P, Herrman H, Bloch S, Benson A, Colusa S. Caring for relatives with serious mental illness: the development of the Experience of Caregiving Inventory. Soc Psychiatry and Psychiatr Epidemiol 1996; 31: $137-48$.

43 Van den Berg B, Spauwen P. Measurement of informal care: an empirical study into the valid measurement of time spent on informal caregiving. Health Econ 2006; 15: 447-60.

44 McManus S, Mowlam A, Dorsett R, Stansfeld S, Clark C, Brown V, et al. Mental Health in Context: The National Study of Work-Search and Wellbeing. Department of Work and Pensions, Research Report 810, 2012 (http:// statistics.dwp.gov.uk/asd/asd5/rports2011-2012/rrep810.pdf).

45 Department of Health. No Health without Mental Health. A Cross Government Mental Health Outcomes Strategy for People of all Ages. Department of Health, 2011(https://www.gov.uk/government/uploads/ system/uploads/attachment_data/file/135457/dh_124058.pdf.pdf)

46 Department of Health. Carers at the Heart of 21st-Century Families and Communities. A Caring System on your Side. A Life of your Own. Department of Health, 2008 (https://www.gov.uk/government/uploads/system/uploads/ attachment_data/file/136492/carers_at_the_heart_of_21_century families.pdf).

47 Jones R, Mackenzie A, Greenwood N, Atkins C, Habbibi R. Evaluation of the Pilot GP Training Programme on Carers. Kingston University \& St George's, University of London, 2010 (http://eprints.kingston.ac.uk/16429/).

48 Princess Royal Trust for Carers, Royal College of General Practioners. Supporting Carers: An Action Guide for General Practioners and their Teams. PRTC and RCGP, 2011. (http://static.carers.org/files/prtc-final-3640.pdf).

49 Carers UK. Improving GP Support for Carers. Carers UK, no date (http://www.carersuk.org/get-involved/carer-ambassadors).

50 Arksey H, Hirst M. Unpaid carers' access to and use of primary care services. Prim Health Care Res Dev 2005; 6: 101-16. 